\title{
O ensino do léxico pelo recorte da coesão nominal
}

\author{
Maria Bernadete Rehfeld \\ Universidade Federal de Minas Gerais (UFMG), Belo Horizonte, Minas Gerais, Brasil \\ bernadeterehfeld@hotmail.com
}

\section{DOI: http://dx.doi.org/10.21165/el.v46i1.1665}

\begin{abstract}
Resumo
Este trabalho investiga o uso que concluintes do Ensino Médio fazem dos recursos de coesão nominal para construir textos escritos, do tipo teórico-opinativo. Propõe o ensino de línguas pela Abordagem Lexical, o ensino do léxico pelo desenvolvimento da competência lexical, aborda a coesão nominal sob o enfoque do Interacionismo Sociodiscursivo e subdivide as anáforas nominais em correferenciais e não correferenciais. O objetivo foi explicar a dificuldade demonstrada por muitos alunos, ao afinal da Educação Básica, na construção dessas cadeias anafóricas. O corpus da pesquisa foi constituído por textos empíricos, produzidos por estudantes em situação de vestibular. Os dados foram coletados por amostragem, abarcando as quatro grandes áreas do conhecimento e sua coleta foi interrompida pelo princípio da saturação teórica. A coleta foi realizada de acordo com observáveis de natureza semântica, léxico-sintática e paralinguística. Os resultados evidenciaram a predominância da repetição lexical, dos sinônimos, dos nomes genéricos, entre as anáforas correferenciais; a dos merônimos, entre as não correferenciais, e apontaram a necessidade de um trabalho pontual com os demais recursos.
\end{abstract}

Palavras-chave: língua escrita; competência lexical; texto teórico-opinativo; coesão nominal.

\section{La enseñanza del léxico por el encuadre de la cohesión nominal}

\section{Resumen}

Este trabajo investiga el uso de los recursos de cohesión nominal para construir textos escritos en el orden teórico-argumentativo. Propone la enseñanza de lenguas desde el Enfoque Lexical, la enseñanza del léxico por el desarrollo de la competencia lexical, el abordaje a la cohesión nominal bajo el enfoque del Interaccionismo Socio discursivo y subdivide las anáforas en correferenciales y no correferenciales. El objetivo fue explicar la dificultad demostrada por diversos alumnos, al final de la Educación Básica, en la construcción de esas cadenas anafóricas. El corpus de la investigación fue constituido por textos empíricos, hechos por estudiantes en situación de examen de ingreso a la universidad. Los datos fueron colectados por muestras, abarcando las cuatro áreas del conocimiento y su colecta interrumpida por el principio de la saturación teórica. La recaudación fue realizada de acuerdo con observaciones de naturaleza semántica, lexicosintáctica y paralingüística. Los resultados evidenciaron la predominancia de la repetición lexical, de los sinónimos, de los nombres genéricos, entre las anáforas correferenciales; la predominancia de los merónimos, entre las no correferenciales, y señalan la necesidad de un trabajo puntual con los demás recursos.

Palabras-clave: lengua escrita; competencia lexical; texto teórico-argumentativo; cohesión nominal.

\section{Introdução}

Esta pesquisa tem por tema o ensino do léxico e pretende investigar o uso que concluintes do Ensino Médio fazem das anáforas nominais como um dos recursos para construir a coesão de textos escritos, do tipo teórico-opinativo. A opção por tais textos 
deve-se ao fato de ser esse o tipo cujo domínio, prioritariamente, espera-se dos alunos ao final da Educação Básica. Uma das competências no uso da língua a serem desenvolvidas por eles ao longo de sua formação escolar é a de expor ideias a respeito de um tema e posicionar-se, criticamente, sobre ele.

O interesse pelo estudo do léxico teve sua origem em um trabalho em sala de aula, com turmas de $3^{\circ}$ ano, numa escola da rede municipal de Belo Horizonte/MG, sobre a seleção vocabular nos textos opinativos produzidos pelos alunos. Nessas produções, muitos deles demonstravam dificuldades com as escolhas lexicais, evidenciando a necessidade de um trabalho direcionado para a questão. $O$ trabalho iniciou-se com a abordagem das inadequações vocabulares e evoluiu para a das cadeias anafóricas que eles construíam. A dificuldade desses alunos em operar com o léxico adequadamente revelou um problema, o qual se tornou objeto de pesquisa e de cuja análise serão mostrados, a seguir, alguns resultados.

Com a proposta de investigar o uso do léxico em sua dimensão textual, compartilhada com Antunes (2012), buscou-se destacar a relevância de vários aspectos lexicais na construção dos textos. De acordo com Antunes (2012, p. 24), é preciso "ver o léxico como elemento da composição do texto, em suas funções de criar e sinalizar a expressão de sentidos e intenções, os nexos de coesão, as pistas da coerência". O léxico tem, pois, uma função estruturante, ou seja, ainda nas palavras da autora "concorre para a 'armação do texto', para a sua 'arquitetônica' [...] (ANTUNES, 2012, p. 62).

\section{Pressupostos teóricos}

O presente trabalho apoia-se na concepção interacionista sociodiscursiva de linguagem/língua/texto em que a linguagem é compreendida como atividade social, a língua como uma entidade sistêmica e, ao mesmo tempo, sócio-histórica, o que implica abordá-la não mais apenas em seus elementos internos - os subsistemas fonológico, morfossintático e semântico -, mas na sua relação com fatores de natureza pragmática, tais como as condições de produção, circulação e recepção do texto; este como uma unidade concreta de produção de linguagem, que pertence necessariamente a um gênero e apresenta traços das decisões do produtor em face de sua situação de comunicação.

O estudo ancora-se nas concepções teórico-metodológicas de Lewis (1997), Ferraz (2010), Bronckart (1999) e Marcuschi (2005). De Lewis (1997), adota-se a concepção de léxico como o "coração" de uma língua e sua Abordagem Lexical (The Lexical Approach). De Ferraz (2010), considera-se a proposta de seu ensino pelo desenvolvimento da competência lexical. De acordo com esse autor,

A competência léxica do falante caracteriza-se como o domínio da parte geral do léxico, no que diz respeito ao sistema das unidades lexicais, e o domínio dos padrões léxicos responsáveis pela realização, produção e interpretação dessas mesmas unidades, em discursos orais ou escritos, assim como para a formação de novas unidades consideradas boas ou aceitáveis ou ainda para a possibilidade de prevenir a formação de unidades inaceitáveis. (FERRAZ, 2010, p. 1847) ${ }^{1}$

\footnotetext{
${ }^{1}$ La competencia léxica del hablante se caracteriza como el dominio de la parte del léxico general, en lo que dice respecto al sistema de las unidades léxicas, y el dominio de los patrones léxicos responsables por la realización, la producción y la interpretación de estas mismas unidades, en discursos orales o escritos, así como para la formación de las nuevas unidades consideradas buenas o aceptables o aún para la
} 
No tocante ao ensino do português, o estudo propõe para o professor tomar o léxico como ponto de partida para a aprendizagem do idioma materno, desenvolvendo com seus alunos atividades nas quais ele seja explorado não como lista de palavras para serem memorizadas, como ocorre em sua abordagem tradicional, mas como um conjunto de unidades sobre as quais regras se aplicam, para combiná-las e produzir um todo portador de sentido: o texto. A proposta é que o professor trabalhe com o léxico gramaticalizado, como defende Lewis (1997), e não com a gramática lexicalizada, como na pedagogia ainda usual em muitas salas de aula.

Para desenvolver a competência lexical dos estudantes, esta pesquisa propõe o trabalho com o léxico pelo recorte da coesão nominal, isto é, pela relação que as palavras estabelecem umas com as outras na sequência do texto, compondo cadeias anafóricas, o que significa focalizá-lo em sua dimensão textual. Não mais, portanto, o ensino do léxico por meio de palavras isoladas, apartadas de sua situação de uso, mas por meio delas em dado contexto, selecionadas pelo usuário conforme seus propósitos comunicativos. $\mathrm{O}$ interesse pelo ensino da coesão nominal deve-se ao fato de ela constituir um mecanismo complexo, variado e altamente relevante para a construção dos textos.

De Bronckart (1999), adotou-se a abordagem da produção textual pela ótica do Interacionismo Sociodiscursivo (ISD), que privilegia as ações verbais e não verbais realizadas pelo produtor numa dada situação de linguagem e os textos engendrados por elas. Para o autor, são as ações e os textos as unidades de análise de um trabalho com a expressão escrita. Inspirando-se na teoria bakhtiniana dos gêneros do discurso, o ISD considera a situação social de produção do enunciado/texto como a base que orientará a ação de linguagem, definindo três subconjuntos de operações, entre eles, o das escolhas linguísticas, para a marcação das fases do plano do texto, para a coesão e para a modalização dos enunciados. Isso quer dizer que o ISD propõe, em primeiro lugar, a análise das ações de linguagem na sua relação com o mundo social e a intertextualidade para, em seguida, analisar a arquitetura interna do texto e o papel desempenhado pelos elementos da língua.

De Bronckart (op. cit.), incorporou-se, ainda, o conceito de anáfora como uma relação de correferência entre um sintagma nominal ( $\mathrm{SN})$, que introduz uma unidade nova de significação, e um outro, que a retoma. Ao primeiro, o autor chama unidade-fonte (UF) ou antecedente, origem da cadeia; ao segundo, anáfora (ANF), SN que reformula a unidade-fonte no curso do texto. A unidade que retoma outra aparece inserida nas estruturas oracionais - é um constituinte interno da frase - e desempenha aí as funções de sujeito, atributo, complemento etc. O texto apresenta um efeito de estabilidade ou continuidade, assegurando a manutenção temática e, consequentemente, a unidade de sentido, como em (01), onde a UF tornados é retomada pela ANF o destruidor redemoinho:

(01) Tornados são um fenômeno tão fantástico e devastador que parecem coisa de Hollywood - de O mágico de $\mathrm{Oz}$ a Twister. $\mathrm{Na}$ segunda-feira, dia 20, o destruidor redemoinho mostrou sua assustadora força na vida real. (Época, n. 783, p. 18)

Também de Bronckart (1999), adotou-se a classificação das anáforas em pronominais e nominais e optou-se pelas últimas, como em (01) acima, por

posibilidad de prevenir la formación de unidades inaceptables. 
desempenharem funções sociocognitivo-discursivas de grande relevância na produção textual: (a) mobilizam saberes diversos; (b) organizam a macroestrutura textual; (c) encapsulam e rotulam porções de informação no texto; (d) imprimem orientação argumentativa aos enunciados e (e) veiculam diferentes vozes sociais, além de sua função prototípica de manter o tópico do texto. Ao lado dessas funções, outro motivo para a opção pelas anáforas nominais é o fato de elas se relacionarem com a tipologia textual.

Quanto à mobilização de conhecimentos diversos, pesquisas sobre o tema têm mostrado que as anáforas nominais ativam não apenas saberes linguísticos, mas também extralinguísticos, tais como o conhecimento enciclopédico e o compartilhado entre produtor e leitor. No que se refere à função de organizar o texto, Koch (2009) afirma que ela auxilia o desdobramento do tópico central em subtópicos, orientando a estruturação do texto e propiciando a progressão temática e a articulação entre seus enunciados. No tocante à função encapsuladora e rotuladora, certo grupo de anáforas resume segmentos de texto, sumarizando-os sob rótulos abstratos e genéricos. Tais anáforas, ainda segundo Koch (2009), resumem e rotulam uma parte do cotexto que as precede (x é um acontecimento, um fato, um fenômeno, uma hipótese, uma cena etc.) ao mesmo tempo que introduzem uma nova unidade-fonte, que passará a constituir um tema específico para os enunciados subsequentes.

O que concerne à função argumentativa, formas nominais anafóricas constituem uma marca da avaliação que o produtor faz acerca de seu objeto de discurso e, consequentemente, da posição assumida diante dele, direcionando seu interlocutor para determinadas conclusões. Isso quer dizer que suas escolhas lexicais não são neutras, mas trazem consigo uma carga ideológica. Nas escolhas que faz, o produtor vai operando com transformações no objeto de discurso, por meio de recategorizações e, assim, construindo seu ponto de vista sobre ele.

Em sua função argumentativa, as anáforas nominais não só veiculam o ponto de vista do produtor, como também trazem à cena interlocutiva outras vozes sociais, mobilizando o interdiscurso e evidenciando o texto como um espaço polifônico. Cavalcante, Brito e Filho (2014, p. 124) ressaltam que "A quem enuncia, é facultada uma série de recursos para estabelecer a articulação entre as vozes, necessária ao seu projeto de dizer. Entre estes, os processos referenciais são bastante relevantes." As anáforas nominais cumprem, portanto, um duplo papel: reelaboram um objeto de discurso no desenvolvimento do texto, marcando a posição do produtor e orientando o leitor para a adesão ao mesmo ponto de vista, além de trazerem para a situação comunicativa diferentes posicionamentos.

Finalmente, sobre a relação entre anáforas nominais e tipologia textual, é preciso observar que, nos discursos teóricos que, frequentemente, articulam séries de argumentos de caráter abstrato, as nominais são, conforme Bronckart (1999), nitidamente as mais frequentes e, geralmente, associadas a relações complexas de contiguidade, inclusão, associação, implicação etc.

De Marcuschi (2005), este trabalho agrega a subdivisão das anáforas em correferenciais e não correferenciais. O primeiro grupo inclui aquelas em que anáfora e unidade-fonte designam o mesmo referente, como em (01), onde tornados e o destruidor redemoinho nomeiam o mesmo referente tornados; o segundo, em que elas designam referentes diversos, embora de alguma forma relacionados entre si, como em (02) a seguir: 
(02) A guerra permanente, decretada após os atentados de 11 de setembro de 2001, permitiu que Washington lançasse mão de práticas pouco condizentes com o que a maior potência do planeta representa. (Época, n. 784, p. 10)

Em (02), a unidade-fonte Washington e a anáfora a maior potência do planeta nomeiam referentes distintos: o da primeira é a capital federal dos Estados Unidos; o da segunda; o próprio país. Apesar de diferentes, há, entre unidade-fonte e anáfora, uma relação de contiguidade - a primeira refere-se à parte; a segunda, a todo - o que permite, pois, que a cadeia anafórica se configure. Neste caso, a relação entre unidade-fonte e anáfora está implícita e precisa ser inferida.

As anáforas correferenciais foram subdivididas em três grupos: (a) por repetição lexical; (b) por variação lexical e (c) por encapsulamento. Fazem parte do grupo (a) aquelas constituídas pelo mesmo núcleo nominal da unidade-fonte, acompanhado ou não de item recategorizador; do grupo (b), os sinônimos, os hiperônimos, os hipônimos e as descrições definidas; do grupo (c), os nomes genéricos e as nominalizações. Quanto às não correferenciais, foram subclassificadas em nomes metalinguísticos e anáforas indiretas, que incluem merônimos e associações semânticas.

A proposta de distribuição das anáforas nominais em cinco grupos - por repetição lexical, variação lexical, encapsulamento, nome metalinguístico e anáforas indiretas tem implicações metodológicas e pedagógicas para este estudo. Metodologicamente, essa divisão é mais econômica, porque reúne, em poucos grupos apenas, os diferentes tipos de anáforas; pedagogicamente, por permitir pensar em sua transposição para a sala de aula.

Merece uma observação à parte o grupo das anáforas cujo núcleo é um nome genérico. Embora o objeto de discurso dessa cadeia não apareça, no cotexto, explicitamente nomeado na unidade-fonte, de acordo com Cavalcante, Filho e Brito (2014), a relação que aí se estabelece é correferencial, pois o objeto de discurso vai sendo construído gradativamente na porção anterior do texto. Isso significa que ele não é necessariamente pontual e explicita-se sob um rótulo cujo núcleo é um nome geral, como mostra o exemplo (03):

(03) Vivemos hoje uma conjunção de situações-limite. Há seis meses, em outubro de 2011, chegamos a 7 bilhões de pessoas. Mais recentemente, no fim do mês passado, a Agência Internacional de Energia (AIE) divulgou a preocupante informação de que a emissão de dióxido de carbono $\left(\mathrm{CO}_{2}\right)$ [...] bateu recorde. A tais fatos, acrescente-se a persistente indefinição quanto aos termos do acordo que vai substituir o Protocolo de Kyoto... (Estado de Minas, 10 jun. 2012, p. 2)

Em (03), ao resumir a porção Há seis meses, em outubro de 2011, chegamos a 7 bilhões de pessoas. Mais recentemente, no fim do mês passado, a Agência Internacional de Energia (AIE) divulgou a preocupante informação de que a emissão de dióxido de carbono $\left(\mathrm{CO}_{2}\right)$ [...] bateu recorde como tais fatos, o produtor está apenas nomeando um objeto de discurso que vinha se construindo. Ou, nos termos de Cavalcante, Filho e Brito (op. cit., p. 80), o objeto de discurso "[...] já vinha sendo traçado e apenas se confirma com o emprego da anáfora encapsuladora".

Segue, abaixo, exemplo para os outros tipos de recursos anafóricos: repetição lexical, sinonímia, meronímia em (04); hiperonímia em (05); hiponímia em (06); descrição definida em (07); nominalização, nome metalinguístico e associação semântica em (08), (09) e (10), respectivamente. 
(04) Conservar a mata implica conter a expansão desordenada de cidades. Acabar com a produção ilegal de carvão vegetal que alimenta as siderúrgicas. E monitorar cortes ainda que do tamanho de um empreendimento imobiliário. Na semana passada, a prefeitura de São Paulo autorizou o corte de 1.787 árvores para um condomínio. Parece uma derrubada inexpressiva, mas tirou mais um naco da Mata Atlântica do mapa. (Época, n. 785, p. 12)

Em (04), destacam-se três cadeias anafóricas: (a) uma constituída pela relação de repetição do SN cortes, recategorizado, em o corte de 1.787 árvores; (b) outra constituída pela relação sinonímica entre o núcleo nominal corte, do $\mathrm{SN}$ o corte de 1.787 árvores, e o núcleo derrubada, do SN uma derrubada inexpressiva, e (c) uma terceira constituída pela relação meronímica entre os SNs de um empreendimento imobiliário e para um condomínio.

(05) ... "O que não pode é haver um desequilíbrio que rompa todo o sistema", afirma o gerente de Meio Ambiente da Federação das Indústrias do Estado de Minas Gerais (Fiemg), Wagner Soares Costa. $A$ entidade levará para o Rio a experiência mineira dos setores alcooleiro, florestal, têxtil, siderúrgico... (Estado de Minas, 10 jun. 2012, p. 2)

Em (05), a unidade-fonte Federação das Indústrias do Estado de Minas Gerais nomeia uma subclasse de pessoa jurídica que é retomada por meio de sua categoria geral, entidade.

(06) [...] Nossa água da chuva, água potável, tempo, clima, litorais, grande parte da nossa alimentação e até mesmo o oxigênio do ar que respiramos são, em última análise, todos fornecidos e regulados pelo mar. Ao longo da história, oceanos e mares têm sido canais vitais para o comércio e transporte. (Estado de Minas, 10 jun. 2012, p. 3)

Em (06), a unidade-fonte pelo mar, cujo núcleo nomeia uma categoria geral, mar, é retomada por um $\mathrm{SN}$ cujos núcleos, oceanos e mares, designam subcategorias da primeira, estabelecendo uma cadeia anafórica com base na relação geral/particular.

(07) Quanto maior o número de pessoas, maior a demanda por energia que, para ser produzida, depende primordialmente, ainda hoje, do petróleo. E são justamente os derivados do líquido negro os principais responsáveis pelo aumento das emissões de dióxido de carbono $\left(\mathrm{CO}_{2}\right)$ na atmosfera. (Estado de Minas, 10 jun. 2012, p. 5)

Em (07), a anáfora líquido negro pressupõe que o leitor compartilhe com o produtor o conhecimento sobre petróleo como uma fonte de energia em estado líquido e de cor negra ao mesmo tempo que pode lhe trazer como novas essas informações, caso este suponha que aquele não as tenha.

(08) Para o diretor da S.O.S Mata Atlântica, não tem sentido em se produzir soja em Alta Floresta, no Mato Grosso e fazer todo o transporte por caminhão até o Porto de Paranaguá. [...] O correto é que essa produção ocorra próximo aos locais de embarque, em áreas já desmatadas. (Estado de Minas, 10 jun. 2012, p. 9)

Em (08), o núcleo produção, da anáfora essa produção, resulta de uma operação que, pelo processo de derivação, converte um verbo, produzir, em nome.

(09) A Rio +20 terá como um dos temas centrais a economia verde. A expressão foi cunhada pelo Programa das Nações Unidas para o Meio Ambiente (Pnuma) para ser oficialmente usada durante a conferência. (Estado de Minas, 10 jun. 2012, p. 5) 
Em (09), a anáfora a expressão focaliza a atividade enunciativa que a unidadefonte a economia verde desempenha no cotexto.

(10) Nunca tantas pessoas escaparam da miséria quanto agora. O caso da China é emblemático. Desde 1981, cerca de 600 milhões de chineses saíram da penúria. O Brasil não fíca atrás. De 2003 até agora, 28 milhões de brasileiros deixaram a pobreza e 39,5 milhões chegaram à considerada classe média - que, segundo o governo federal, é o extrato da população que tem renda familiar per capita entre R\$291 e R\$1.019. A inclusão social e o acesso a melhores condições de vida são fatos a serem comemorados. (Estado de Minas, 10 jun. 2012, p. 8)

Em (10), não há retomada de uma unidade-fonte, mas a formação de uma cadeia associativa estabelecida pela proximidade de sentidos entre um grupo de formas nominais: assim, a saída da pobreza associa-se à classe média, que se associa à renda familiar per capita, que se associa à inclusão social e ao acesso a melhores condições de vida, compondo uma rede de significações.

\section{A metodologia: a constituição do corpus e a coleta dos dados}

A investigação, cujos resultados se apresentam aqui, tem como corpus de análise textos empíricos produzidos por candidatos a um concurso vestibular, como parte da prova de Língua Portuguesa. Sendo o corpus composto de textos produzidos para esse tipo de exame, os sujeitos dessas produções foram, principalmente, alunos que concluíram recentemente o Ensino Médio.

A definição do corpus foi feita de acordo com os seguintes critérios: (a) levantamento dos dados por amostragem, segundo Günther (2006), em virtude da necessidade de recorte no número de textos; (b) seleção dos textos em função das quatro grandes áreas do conhecimento (Biomédica, Exatas, Humanas e Econômicas) e (c) uso do princípio da saturação teórica, formulado por Glaser e Strauss (1967), para nortear a finalização da coleta de dados.

O levantamento dos dados por amostragem assegura, conforme Günther (2006), uma maior representatividade e permite generalização para uma população mais ampla. Partindo de produções individuais, acredita-se ser possível fazer generalizações sobre o uso que concluintes do Ensino Médio fazem da coesão nominal, o que, espera-se, possa converter-se num conjunto de parâmetros a orientar o trabalho do professor e a elaboração de material didático sobre o tema.

Na seleção dos textos, buscou-se contemplar as quatro áreas do conhecimento a fim de que o corpus fosse abrangente e permitisse uma visão ampla sobre o processo de escrita do público-alvo. Foi escolhido um curso de cada área: Medicina, Engenharia de Controle e Automação, Letras e Administração, respectivamente. Para a área de Humanas, incluiu-se, ainda, o de Pedagogia. Os cursos foram escolhidos de forma aleatória, uma vez que o objetivo era abarcar um universo variado de textos.

A opção por incluir as redações de candidatos ao curso de Pedagogia na pesquisa deve-se ao fato de, ao lado de Letras, ambos terem a língua como seu objeto de estudo e/ou de ensino. Como professores da Educação Básica, os futuros profissionais, neles formados, devem ter o domínio de sua língua materna, que inclui, entre outros mecanismos, o da coesão textual, pois esse conhecimento será um dos objetos de trabalho em suas áreas de atuação. 
Definidos os cursos, que perfizeram cinco, foram selecionados, também aleatoriamente, dez textos de cada um deles, numerados de 1 a 10 . Chegou-se a esse número, porque, em observância ao princípio da saturação teórica, identificou-se, nesse ponto, certa redundância nos dados: as informações levantadas não estavam contribuindo, de modo relevante, para o aperfeiçoamento da análise e da interpretação do corpus.

Constituído o corpus, a coleta dos dados foi feita segundo o procedimento de observação, proposto por Bronckart (1999). Esse procedimento envolve três subconjuntos de observáveis: os de ordem semântica, os de ordem léxico-sintática e os de ordem paralinguística.

Os observáveis de ordem semântica incluem informações acerca do efeito global de significação que o texto produz no leitor; os de ordem léxico-sintática, informações sobre as escolhas lexicais do produtor, assim como as regras sintáticas usadas por ele para constituir os enunciados do texto; os de ordem paralinguística, informações a respeito de procedimentos supratextuais de formatação da página, tais como título e paragrafação, ou de relevo, como o uso de aspas e sublinhados.

A coleta dos dados iniciou-se com a leitura dos textos, cujo objetivo foi buscar, primeiramente, informações sobre os elementos constitutivos do texto. Após a leitura inicial, que proporcionou uma visão global dos textos, a pesquisadora realizou outras, concentrando-se nos observáveis de ordem léxico-sintática, sem deixar de convocar os de ordem semântica e os de ordem paralinguística, quando necessários para explicar sua ação conjunta com os primeiros.

A coleta foi dividida em dois momentos: (a) o da identificação das cadeias anafóricas, sua classificação, quantificação por tipos e análise e (b) o do levantamento das cadeias anafóricas relativas aos três principais referentes na proposta de desenvolvimento do tema, sua evolução no curso do texto e análise.

O objetivo, no primeiro momento, foi identificar a ocorrência de cadeias anafóricas nos textos dos vestibulandos, sua adequação ou não em função das escolhas lexicais, sua tipificação e o número de ocorrências por tipo; no segundo momento, o alvo foi verificar como as escolhas feitas refletiam o grau de apropriação pelo produtor dos parâmetros sociodiscursivos e sua mobilização na realização da ação de linguagem proposta.

\section{A proposta de ação de linguagem}

$\mathrm{Na}$ perspectiva do Interacionismo Sociodiscursivo de Bronckart (1999), a proposta de ação de linguagem constitui um conjunto de operações a serem realizadas pelo produtor num dado contexto sociodiscursivo. Quanto à sua dimensão social, a atividade linguageira pressupõe que o produtor considere o lugar e o tempo da produção, sua finalidade, o destinatário, a imagem que ele constrói deste, de si mesmo e dos outros. Quanto à sua dimensão discursiva, pressupõe o conhecimento do gênero, incluindo o tema, sua estrutura composicional e o estilo verbal.

O contexto social da produção, em análise nesta pesquisa, foi o concurso vestibular, realizado numa universidade particular de Belo Horizonte/MG, em outubro de 2014, cuja finalidade era avaliar candidatos ao Ensino Superior. Essa avaliação envolvia 
competitividade, expectativa de aprovação no exame, entrada na vida acadêmica e a consequente instauração de um novo ciclo na formação intelectual dos estudantes.

Quanto à relação entre produtor e destinatário, o papel social deste é de muita importância para aquele, na medida em que o primeiro vê o segundo como leitor autorizado pela instituição promotora do exame a avaliar seu texto; a si mesmo como sujeito para quem estão estabelecidas coerções relativas ao gênero e ao uso da língua.

Quanto à dimensão discursiva, a ação de linguagem previa, no que tange ao tema, a apresentação de um ponto de vista e a seleção de argumentos válidos para sua sustentação; no que diz respeito à estrutura composicional, o conhecimento do tipo de discurso e da sequência discursiva predominante; no tocante ao estilo verbal, o conhecimento da variante linguística de registro, que inclui escolhas lexicais e morfossintáticas adequadas a ela.

$\mathrm{Na}$ ação de linguagem apresentada pela Comissão Organizadora do Vestibular ao vestibulando, o produtor, no papel social de aluno concluinte do Ensino Médio, menor de idade, deveria produzir um artigo de opinião sobre a proposta de redução da maioridade penal para 16 anos, em debate no Brasil, em 2014, destinado a um interlocutor ausente, no papel social de analista de redação. Na realização do gênero, deveria avaliar a proposta de redução da maioridade penal, posicionando-se a favor ou contra. Para tanto, deveria realizar duas outras ações: formular argumentos pertinentes e convencer, por meio deles, o destinatário, em busca de sua adesão ao mesmo ponto de vista. Uma ação final previa que o produtor propusesse alternativas para o combate à delinquência juvenil. Embora não explicitado na proposta, a ação de linguagem, nesse contexto, pressupunha que o produtor usasse a variante padrão da língua.

\section{Os dados da $1^{\mathrm{a}}$ fase da coleta e sua análise}

$\mathrm{Na}$ leitura dos textos, foram encontradas 1261 ocorrências de anáforas nominais. Entre elas, constatou-se o predomínio de cadeias anafóricas construídas adequadamente, como neste trecho de uma redação, o qual inclui o título e seu primeiro parágrafo: ${ }^{2}$

(11) Delinquência juvenil não é apenas um caso de polícia

A proposta de redução da maioridade penal para 16 anos agrada a maior parte da população, segundo as pesquisas de grandes veículos de comunicação, como a "Carta Capital". No entanto, percebo como jovem que essa visão é bastante simplista e ignora a situação de risco social a que a maioria dos jovens mais pobres estão submetidos em nosso país e a qual eu estou inserido. É uma medida meramente reativa, que não vai até as causas do problema. Redação 07 - Medicina

Ocorrências de cadeias anafóricas construídas inadequadamente também foram detectadas. A inadequação deve-se às escolhas lexicais impróprias e à mera repetição de um mesmo SN, como nestes exemplos (12) e (13), respectivamente:

\footnotetext{
${ }^{2}$ Uma unidade-fonte e sua(s) respectiva(s) anáfora(s) foram sinalizadas com a mesma cor, para facilitar sua identificação pelos leitores.
} 
(12) Em uma sociedade em que um menor de 16 anos tem a igualdade no direito máximo que é a escolha de um governante para seu país, só nos basta perguntar o que lhes diferenciam dos demais constituidores da sociedade. (Redação 03 - Administração)

(13) O governo deve melhorar a educação do país através da ampliação das infraestruturas escolares, aumentar o salário e a qualidade dos professores, oferecer atividades que promovem o desenvolvimento físico, psicológico e cultural dos jovens, elevar o fornecimento de material escolar e programas que guiam os pais ou responsáveis de como educar os jovens dentro de casa.

Dessa forma, o governo ao reduzir a maioridade penal para 16 anos estará jogando milhares de jovens no exílio em que prejudicará a formação do indivíduo. E através da educação, irá valorizar o jovem e promover o seu desenvolvimento, contribuindo para a redução da criminalidade e o desenvolvimento do país, já que os jovens são o futuro da nossa nação. Redação 05 - Engenharia $\mathrm{C} / \mathrm{A}$

Em (12), o emprego do item lexical constituidores, na construção da anáfora, configura uma impropriedade vocabular, pois uma sociedade compõe-se de membros, de integrantes. Em (13), o problema deve-se à mera repetição do mesmo núcleo nominal, jovens, o que denota pouca atenção à possibilidade de variação no item lexical por parte do agente produtor.

Quanto ao tipo, foram encontradas, no corpus, anáforas correferenciais e não correferenciais, construídas com os diversos recursos disponíveis na língua. Entre as do primeiro grupo, verificou-se a ocorrência de formas anafóricas nominais por repetição lexical, sinonímia, hiperonímia, hiponímia, descrição definida, nome genérico e nominalização; entre as do segundo grupo, anáforas por nome metalinguístico, meronímia e associação semântica.

As ocorrências foram quantificadas numérica e percentualmente. A Tabela 1, a seguir, mostra essa quantificação.

Tabela 1. Quantificação das anáforas nominais por tipo de recurso

\begin{tabular}{|c|c|c|c|c|}
\hline \multicolumn{3}{|c|}{ Anáforas nominais } & $\begin{array}{c}\mathbf{N}^{\mathbf{0}} \text { de } \\
\text { ocorrências } \\
\end{array}$ & $\begin{array}{c}\text { Percentual de } \\
\text { ocorrência }\end{array}$ \\
\hline \multirow{8}{*}{ Correferenciais } & \multicolumn{2}{|c|}{ por repetição lexical } & 415 & $33 \%$ \\
\hline & \multirow{4}{*}{ por variação lexical } & Sinônimo & 177 & $14 \%$ \\
\hline & & Hiperônimo & 101 & $08 \%$ \\
\hline & & Hipônimo & 100 & $08 \%$ \\
\hline & & descrição definida & 23 & $02 \%$ \\
\hline & \multirow[t]{2}{*}{ encapsulamento } & nome genérico & 163 & $13 \%$ \\
\hline & & Nominalização & 38 & $03 \%$ \\
\hline & \multicolumn{2}{|c|}{ nome metalinguístico } & 34 & $03 \%$ \\
\hline \multirow{2}{*}{$\begin{array}{l}\text { Não } \\
\text { Correferenciais }\end{array}$} & \multirow{2}{*}{ anáfora indireta } & Merônimo & 193 & $15 \%$ \\
\hline & & associação semântica & 17 & $01 \%$ \\
\hline \multicolumn{3}{|l|}{ Total } & 1.261 & $100 \%$ \\
\hline
\end{tabular}

Os achados evidenciaram o predomínio das anáforas por repetição lexical sobre todas as outras, seguidas daquelas cujos núcleos são sinônimos e nomes genéricos, entre as correferenciais, e merônimos, entre as não correferenciais. Essa prevalência parece 
explicar-se por serem os três primeiros recursos aqueles mais imediatamente acessíveis ao produtor, exigindo dele baixo esforço cognitivo; o quarto, por ser a unidade-fonte apenas uma âncora para a anáfora, não ocorrendo entre elas nem correferencialidade, nem retomada. Em contrapartida, uma menor ocorrência de anáforas por hiperônimos e hipônimos parece advir do fato de serem esses recursos dependentes de conhecimentos enciclopédicos, e um percentual ainda mais reduzido de descrições definidas, nominalizações, nomes metalinguísticos e associações semânticas, por tais recursos dependerem de saberes outros, como o compartilhado e o de metalinguagem.

\section{Os dados da $2^{\mathrm{a}}$ fase da coleta e sua análise}

Dos resultados obtidos na $1^{a}$ fase, emergiu a necessidade de focalizar o tratamento dado pelos vestibulandos aos três referentes centrais no desenvolvimento do tema - a redução da maioridade penal para 16 anos, a delinquência juvenil e o jovem -, por serem eles sobre os quais os produtores deveriam realizar suas ações de linguagem. O objetivo foi verificar como estes os lexicalizavam em unidades-fonte e depois as retomavam ou a elas remetiam, construindo a cadeia anafórica. Outros referentes, presentes nos textos, não foram considerados neste segundo momento, devido à sua variabilidade em função do projeto de dizer de cada produtor.

Nessa etapa, fez-se o levantamento das cadeias também por curso, considerandose as escolhas léxico-sintáticas do produtor para cada um deles. Verificou-se que, em todos os cursos, eles usaram diferentes recursos para construir essas cadeias e, mesmo no caso da repetição lexical, o núcleo da anáfora vinha acompanhado de item(ns) recategorizador(es), como mostra o exemplo (18), a seguir:

(18) Referente 1: < a proposta de redução da maioridade penal para 16 anos>3

UF: A proposta de redução da maioridade penal para 16 anos

ANFs: essa visão $=$ demonstrativo + nome genérico

uma medida meramente reativa $=$ artigo + nome genérico + advérbio + adjetivo

uma visão mais crítica $=$ artigo + repetição de núcleo nominal + advérvio + adjetivo

Referente 2: <a delinquência juvenil>

UF: Delinquência juvenil

ANFs: do problema $=$ contração preposição + artigo + nome genérico

pelo crime $=$ contração preposição + artigo + hiperônimo

um delinquente $=$ artigo + merônimo

os atos criminosos $=$ artigo + nome genérico + adjetivo

o crime $=$ artigo + repetição de núcleo nominal

a delinquência juvenil $=$ artigo + repetição de $\mathrm{SN}$

Referente 3: <o jovem>

UF: como jovem

ANFs:dos jovens mais pobres = contração preposição + artigo + repetição núcleo nominal +

\footnotetext{
${ }^{3}$ Os símbolos $<\mathrm{e}>$ foram usados para sinalizar a realidade extralinguística constitutiva do referente.
} 
advérbio + adjetivo

o jovem que cometeu um crime $=$ artigo + repetição de núcleo nominal + oração adjetiva

ao indivíduo $=$ contração preposição + artigo + nome genérico

Um jovem menor de idade $=$ artigo + repetição de núcleo nominal + expressão adjetiva

do jovem $=$ contração preposição + artigo + repetição de núcleo nominal

os adolescentes e crianças $=$ artigo + hipônimo

aos jovens mais pobres $=$ combinação de preposição + artigo + repetição de SN

o indivíduo $=$ artigo + repetição de núcleo nominal

Redação 07 - Medicina

Os dados da Redação 07 demonstram domínio do léxico pelo produtor, manifestado nas variadas formas de ele compor as anáforas nominais de seu texto e na observância do critério da distribuição no uso da repetição lexical, isto é, de seus pontos de ocorrência na sequência do texto. Essas ações traduzem sua apropriação dos parâmetros sociodiscursivos e sua mobilização ao executar a ação de linguagem proposta, atendendo, com eficiência, às condições de produção e de recepção previstas para essa situação.

Nem todos os produtores, porém, realizaram essas ações, como se vê em (19), abaixo:

(19) Referente 1: <a proposta de redução da maioridade penal para 16 anos>

$\mathrm{UF}$ : a maioridade penal $=$ artigo $+\mathrm{SN}$

ANFs: a maioridade penal para 16 anos = repetição de artigo e SN + SN preposicionado

da lei da maioridade penal aos 16 anos = contração preposição + artigo + hiperônimo +

repetição de $\mathrm{SN}$ e SN preposicionado

Referente 2: <a delinquência juvenil>

UF: Violência

ANFs: A violência $=$ artigo + repetição de núcleo nominal

de violência $=$ preposição + repetição de núcleo nominal

Referente 3: <o jovem>

UF: por jovens $=$ preposição + repetição de núcleo nominal

ANFs: sobre jovens $=$ preposição + repetição de núcleo nominal

jovens $=$ repetição de núcleo nominal

de alunos assim $=$ preposição + hiperônimo + adjetivo genérico

Redação 02 - Pedagogia

Os dados, levantados na Redação 02, mostram o predomínio da repetição lexical, sem recategorização e a não observância do critério de distribuição das anáforas. Tal achado evidencia o domínio básico, apenas, do léxico pelo produtor e seu pouco engajamento na situação comunicativa em que ele se encontrava. Isso parece relacionarse com a argumentação frágil no desenvolvimento do tema, o que, por sua vez, influenciou a quantidade e a qualidade das cadeias anafóricas produzidas por ele. 


\section{Considerações finais}

Tendo como unidades de análise a ação de linguagem e o texto, os achados desta pesquisa mostraram que os produtores que a realizaram, satisfatoriamente, foram, independente do curso a que concorreram, aqueles que demonstraram a apropriação do conjunto dos parâmetros sociodiscursivos previstos para essa ação e sua mobilização ao executá-la, de acordo com a tese defendida pela teoria interacionista bronckartiana.

Em vista dos resultados obtidos, são apresentadas algumas sugestões de trabalhos para o Ensino Médio com alguns aspectos do tema que a pesquisa revelou como dificuldade para muitos estudantes concluintes desse nível escolar. Dentre esses aspectos, estão as repetições lexicais, em parte, relacionadas com a ausência de recategorização do referente pela anáfora e a relação entre cadeias anafóricas e desenvolvimento da argumentação. Nessas situações, defende-se que o trabalho seja feito de modo explícito e sistemático, orientado por seu planejamento.

A proposta para as repetições lexicais faz-se na direção do desenvolvimento, pelo professor, de atividades que levem os alunos a refletir sobre o importante papel cognitivo que elas desempenham na continuidade referencial, apontando-lhes o critério da distribuição para seu uso. O problema a ser evitado nas repetições não são elas mesmas, mas os lugares onde ocorrem no tex to e o modo como são construídas: se muito próximas, em SNs sem recategorização interna, têm baixa informatividade e, por isso, em nada contribuem para a progressão do tema. Se bem distribuídas e constituídas com o acréscimo de novas informações sobre o núcleo nominal, transformam-se em recurso de persuasão.

Sobre a ausência de recategorização do referente na construção do SN anafórico, propõe-se que o professor trabalhe com uma reflexão sobre o papel argumentativo que ela pode assumir no texto, principalmente através do acréscimo de adjetivo ao núcleo nominal, propiciando uma discussão em torno de questões de metalinguagem. Uma dessas questões é o tratamento que a gramática tradicional dá a ele na função de adjunto adnominal. A gramática ensina que, nessa posição, o adjetivo constitui termo acessório da oração, o que pode levar os alunos a vê-lo como um item lexical dispensável. O que seu uso revela, no entanto, é o papel decisivo que ele assume no texto ao contribuir para a construção do ponto de vista pretendido pelo produtor.

Outra questão de metalinguagem é a relação entre sua posição face ao substantivo e o sentido produzido. Sua anteposição ou posposição a este, muitas vezes, determina diferenças de sentido, gerando, por conseguinte, diferenças nos efeitos de sentido.

Quanto ao trabalho com a relação entre cadeias anafóricas e desenvolvimento da argumentação, sugere-se que as atividades, realizadas na sala de aula, levem os estudantes a refletir sobre a alta frequência das anáforas nominais nos textos teórico-opinativos, porque construídas com itens lexicais plenos e, como tal, veiculadores das ideias expressas pelo produtor e do ponto de vista que adota acerca delas. Para argumentar sobre um tema, este precisa construir tais cadeias; ao construí-las, argumenta através das escolhas lexicais que faz. Nessa reflexão, indica-se que o professor dê lugar de destaque às anáforas nominais como poderoso recurso para obter a adesão do leitor ao ponto de vista do produtor. 
Entende-se que a forma de trabalhar com o léxico, apontada aqui, redimensiona seu papel no ensino da língua materna, porque considera os itens em seus contextos de uso. Isso contribui para transformar a visão de língua, disseminada entre os alunos, como entidade estática, homogênea e rígida em outra, na qual ela passa a ser concebida como dinâmica, diversa e flexível, à disposição dos falantes para que eles façam escolhas lexicais de acordo com seus propósitos comunicativos.

\section{REFERÊNCIAS}

ALERTA na Mata Atlântica. Época. São Paulo, n. 785, p. 12, 10 jun. 2013.

ANTUNES, I. Território das palavras: estudo do léxico em sala de aula. São Paulo: Parábola, 2012.

BRONCKART, J. P. Atividade de linguagem, textos e discursos: por um interacionismosociodiscursivo. Tradução de Anna Rachel Machado e Péricles Cunha. São Paulo: EDUC, 1999.

CAVAlCANTE, M. M.; FILHO, V. C.; BRITO, M. A. P. Coerência, referenciação e ensino. São Paulo: Contexto, 2014.

ÉPOCA. São Paulo: Ed. Globo, n. 784, 03 jun. 2013, p. 10.

ESPECIAL Rio+20. Estado de Minas. Belo Horizonte, 10 jun. 2012. Suplemento, p. 2, $3,5,8$ e 9 .

FERRAZ, A. P. El desarrollo de la competencia léxica desde el uso de material auténtico en la enseñanza de PLE. In: CONGRESO INTERNACIONAL DE LINGÜÍSTICA GENERAL, 9, 2010, Valladolid. Actas Del Congreso, Valladolid: Universidad de Valladolid, 2010, p. 1846-1859.

GLASER, B. G.; STRAUSS, A. L. The discovery of grounded theory: strategies for qualitative research. New Brunswich (U.S.A.): Aldine Plublishing Company, 1967. Disponível em: <www.sxf.uevora.pt/wp-content/uploads/2013/03/Glaser_1967.pdf>. Acesso em: 22 out. 2015.

GÜNTHER, H. Pesquisa qualitativa versus pesquisa quantitativa. In: Psicologia: teoria e pesquisa. Brasília, v. 22, n. 2, p. 201-210, 2006.

KOCH, I. V. Introdução à Linguística Textual. 2. ed. São Paulo: WMF Martins Fontes, 2009.

LEWIS, M. The lexical approach: the state of ELT and a forward. Hove: Language Teaching Publications, 1997, cap. 5, p. 89-104.

MARCUSCHI, L. A. Anáfora indireta: o barco textual e suas âncoras. In: KOCH, I. V.; MORATO, E. M.; BENTES, A. C. (Orgs.). Referenciação e discurso. São Paulo: Contexto, 2005, p. 53-101.

NATUREZA devastadora. Época. São Paulo, n. 783, p. 18, 27 maio 2013.

Recebido em: 30/08/2016

Aprovado em: 13/08/2017 